\title{
Intact Grammar in HFA? Evidence from Control and Binding
}

(Janke and Perovic 2015 Lingua: pre-published version)

4 Abstract

5 This study contributes original results to the topical issue of the degree to which grammar is intact in high-functioning children with autism (HFA). We examine the comprehension of binding and obligatory control in 26 HFA children, mean age=12;02, compared with two groups of younger typically developing (TD) children: one matched on non-verbal mental age (MA), mean age=9;09, and the other on verbal MA, mean age=8;09. On the binding task, our HFA group showed a good performance on reflexives on a par with TD matched children, in line with recent reports of intact knowledge of reflexive binding in higher but not lower-functioning children with autism. Their comprehension of personal pronouns was somewhat poorer, with no difference observed between the groups, again supporting the existing literature. Results on the control task, which probed mastery of syntactic relations never previously examined in autism, revealed that both HFA children and the two matched TD groups were at ceiling on single-complement subject control (try) and object control (persuade). However, a considerably poorer attainment on double-complement subject control (promise) was present equally in the HFA group and the verbal MA-matched TD group but not in the non-verbal MA-matched group. Performance on promise correlated with age only in the verbal MA-matched group, whilst in HFA it correlated with general cognitive and language abilities.

These novel findings demonstrate that regular obligatory control and reflexive binding are preserved in HFA. We contrast these results with previous literature that has demonstrated deficiencies with passives and raising in HFA populations. The emerging bifurcation suggests different analyses for the principles underlying these constructions: whereas the latter incorporate movement, control and binding do not. The poor performance on promise supports all previous literature on this lexically and syntactically idiosyncratic construction. Its breaking of locality, which in turn results in a conflict between lexical and syntactic requirements, is exceptional and introduces an extra step of learning. This step appears to be related to maturation in TD children, and to stronger language and cognitive skills in HFA children. 
KEY WORDS: Autism, Syntax, Control, Binding

\section{Introduction}

In this paper we investigate comprehension of two examples of grammar in a group of high-functioning children with autism (HFA) ${ }^{1}$ : obligatory control and binding. Autism Spectrum Disorder (ASD) is a lifelong developmental disability affecting social communication and interaction, associated with restrictive interests and behaviours, which are not a result of a global developmental delay or cognitive disability (American Psychiatric Association, 2013). Individuals with ASD are amply documented as having consistent difficulties with pragmatic aspects of language (e.g. Tager-Flusberg and Anderson, 1991; Happé, 1993; Norbury, 2005; Rundblad and Annaz, 2010), yet their level of grammatical competence has not been clearly established as investigations on complex syntactic structures in this population are still sparse. The heterogeneity in the cognitive and linguistic abilities in this population makes it yet more difficult to draw precise conclusions about their syntactic knowledge. Studies have reported different results for children who are high-functioning (HFA) from those who are lowfunctioning (LFA) (Boucher, 2009), or for children who have a language impairment (ALI) against those whose language is normal (ALN) (Tager-Flusberg, 2006). Recent experimental work points to certain advanced syntactic structures being problematic in both children and adults with ASD. Interestingly, all of these structures involve relations where the position that a phrase is interpreted differs from the position that the phrase is pronounced. That is, they all involve movement. ${ }^{2}$ In a sentence repetition task, Riches, Charman, Simonoff and Baird (2010) found that English-speaking teenagers with ALI made significantly more errors than age-matched typically developing (TD) children on subject and object relative clauses. A severe difficulty in the comprehension of subject and object relative clauses is reported in Durrleman and Zufferey (2013) in HFA French-speaking adults, while Zebib, Tuller, Prévost and Morin (2013) found that French-speaking children with ASD would avoid fronted whquestions in an elicitation task by opting for a more simple alternative (e.g. wh-in situ)

\footnotetext{
${ }^{1}$ High-functioning autism (HFA) usually refers to individuals diagnosed with ASD whose IQ is above 80, though some studies use a lower benchmark of IQ of 70 and above.

2 The framework adopted here is that of generative grammar. For introduction and definition of relevant terminology the reader is referred to texts such as Radford (2004); Cook and Newson (2007); Isac and Reiss (2013).
} 
whenever possible. These three studies focused on dependencies that involve A-bar movement, however, constructions involving Argument movement (from here on Amovement), such as passives and raising, have also been reported to cause children with ASD difficulty. ${ }^{3}$ Severely compromised comprehension of passives was revealed in an early study by Tager-Flusberg (1981) and confirmed more recently in Perovic, Modyanova and Wexler (2007). The latter study also reported a deficient comprehension of raising in their sample of children with ASD. At this point then we can see that the few studies conducted in this area have shown that a number of constructions represented in standard formal theories as involving movement seem to be causing difficulty to individuals with ASD. These involve A and A-bar dependencies, as well as local and non-local movement, and children across the high- and lowfunctioning divide have exhibited problems with these relations.

A construction that appears not to cause any interpretative difficulties in autistic children at the higher-functioning level of the spectrum is that of reflexive binding, a local syntactic relation which does not involve movement. Perovic, Modyanova and Wexler (2013a, 2013b) report an impaired comprehension of reflexives (himself, herself) in their sample of English-speaking children with LFA, who also had an established language impairment, but an intact interpretation of these elements in an age-matched sample of children classified as HFA, with no accompanying language impairment. Thus we now have an example of syntax which is not derived by movement that is preserved in children with HFA.

This brief review of experimental research into the mastery of argument dependencies in the grammar of individuals with autism highlights a number of points. Firstly, it illustrates that more research on higher levels of grammatical ability is crucial to the question of if and how the autistic profile impacts upon grammatical development. The present study represents a contribution in this respect. It takes a hitherto unresearched area of grammar in this population, namely obligatory control, and asks, using the

\footnotetext{
3 In A-movement, a phrase moves to an argument position (e.g. in the passive, an object moves to the subject position). In A-bar movement, a phrase moves to a non-argument position (e.g. in whmovement, an object moves to the left periphery of the clause. See e.g. Rizzi (2013) for further explanation of these terms.
} 
same paradigm as that for binding, raising and passives, whether HFA children exhibit any problems with its comprehension. Theoretical accounts of obligatory control differ according to whether they propose a movement-based analysis or not (see Hornstein, 2001; Boeckx and Hornstein, 2004 for movement-based analyses and Manzini, 1983; Landau, 2000; Janke 2007 for non-movement-based approaches and Kirby, Davies and Dubinsky 2010a for a review of some of the issues relevant to movement vs. nonmovement approaches). Thus the second point of interest is theoretical. The degree to which our current participants succeed with obligatory control will contribute to the debate surrounding its classification. If it is not movement-based, our HFA participants' performance on the construction should pattern more closely with that found for binding, rather than revealing the same deficiencies as those found for raising and passives. This is because aside from not involving movement, binding and obligatory control share other fundamental syntactic properties (see Manzini, 1983; Koster, 1987).

In the next subsection, we set out the properties of binding and relay the acquisition trajectory of these constructions in typical development. In section 1.2, we do the same for obligatory control. This will take us to section 1.3, where we form our predictions with respect to the current study.

\subsection{Binding and its acquisition}

111 Pronominal elements include reflexives (e.g. himself/herself) and personal pronouns

112 (e.g. him/her). Both elements are anaphoric, in that they depend upon a referential 113 antecedent for their interpretation, but they differ in terms of the conditions that 114 regulate this interpretative dependency. In standard formal theory, the regulations are 115 stated as a set of conditions under which a reflexive or pronoun can be bound by an 116 antecedent (see Chomsky, 1986). The conditions regulating reflexives demand a local, 117 c-commanding antecedent for the reflexive. ${ }^{4}$ These properties are illustrated in (1a) 118 and (b) respectively. In (1a), the indices indicate that only the most local argument 119 (John) can be linked to the reflexive, whereas (1b) shows that a non-c-commanding 120 antecedent cannot be linked to the reflexive. C-command is a principle that captures 121 the requirement that an antecedent occur in a structurally higher position in a sentence

\footnotetext{
${ }^{4} \mathrm{~A}$ formal definition of $\mathrm{c}$-command is such that a constituent, ' $\mathrm{X}$ ', $\mathrm{c}$-commands a constituent, ' $\mathrm{Y}$ ' if $Y$ is sister to $X$ or contained within X's sister.
} 
122 than its dependent. By embedding the noun, brother, in a possessive construction, this

123 structural superiority is broken. Pronouns contrast with reflexives in exhibiting an anti-

124 locality requirement. If a pronoun takes a sentential antecedent, that antecedent must

125 not be in a local relation with it: in (1c), the pronoun can refer to Peter or an external

126 referent but not to John.

a. Peter 1 said that John 2 should wash himself $*_{1 / 2}$

b. Peter1's brother2 washed himself $*_{1 / 2}$

c. Peter 1 said that John 2 should wash him ${ }_{1 / * 2 / 3}$

132 Children interpret reflexives accurately by the age of about four, however, pronouns 133 can continue to cause difficulty even at the age of six (Jakubowicz, 1984, Chien and 134 Wexler, 1990). The original methodology (i.e. the truth value judgment task) and the results of early studies have been disputed more recently (Conroy, Takahashi, Lidz and Philips, 2009), however, the finding of a differential comprehension of reflexives versus pronouns has been reported consistently across a range of languages (e.g.

138 French, Russian, Icelandic, Dutch - see Guasti, 2004, for a comprehensive review as well as a discussion of clitic languages, where the effect has not been observed), and

140 with different methods (e.g. forced-choice picture selection: van den Akker, Hoeks, 141 Spenader and Hendriks, 2012).

142 The phenomenon of worse interpretation of pronouns as opposed to reflexives can be 143 understood by looking further at the differing principles underlying these elements' 144 regulation. The interpretation of reflexives is uniform in being regulated syntactically 145 only. Under the structural configuration mentioned above, they are always interpreted 146 as bound variables. In contrast, pronouns can either be bound variables or elements 147 regulated by coreference. ${ }^{5}$ In the former instance, the relation is syntactically 148 determined but in the latter, they are regulated by pragmatic or processing constraints 149 (see Chien and Wexler, 1990 for a pragmatic account; Grodzinsky and Reinhart, 1993 150 for a processing account). In their extra-syntactic guise, pronouns will be liable to 151 failure and this extra level of complexity translates into later acquisition in TD.

\footnotetext{
5 The difference between binding and co-reference is further observed in studies which have investigated children's interpretation of pronouns when bound by quantified antecedents, e.g. in 'Every bear $_{i}$ is washing her'. Here the co-referential reading is not available and the pronoun is successfully interpreted by children as a bound variable (see Guasti, 2004, for a review of relevant literature).
} 
153 The contrast in the acquisition of reflexives and pronouns in TD has also been observed in clinical populations, though it may go in the opposite direction, with reflexives being more difficult to interpret than pronouns. The work undertaken on reflexive binding suggests the construction could serve as a litmus test for a grammatical deficit in a population. Groups known for their grammatical strengths relative to their other cognitive impairments, as, for example, Williams syndrome, perform well on tasks assessing reflexive comprehension (see Perovic et al. 2007;

160 Perovic et al. 2013b; Ring and Clahsen, 2005). Those groups for whom morphosyntactic deficits are well documented, however, exhibit problems on these same tasks (for Down syndrome, see Perovic 2004, 2006; Ring and Clahsen 2005; Sanoudaki and Varlokosta 2014; for LFA children see the references mentioned above). Interestingly, no group differences have been revealed for pronoun interpretation: children with $A S D$, regardless of their high- or low-functioning classification, demonstrated the same variability in their performance as that of the TD children against whom they were matched.

In the next sub-section, we turn to obligatory control, which we will see exhibits a substantial overlap with reflexive binding in terms of its syntactic principles yet includes further components that need to be integrated during acquisition, which culminate in a more complex learning task.

\subsection{Control and its Acquisition}

175 Like reflexives, the understood subject in obligatorily controlled complements must have a local, c-commanding antecedent (see Manzini, 1983; Cohen Sherman and Lust, 1993; Goodluck, Terzi and Diaz, 2001). This can be seen in (2), where in (a), locality permits only 'Peter' to be interpreted as the potential dog walker and in (b), only 'John's brother' (and not 'John') can be, since only the whole possessive NP ccommands into the infinitival clause.

a. John told Peter ${ }_{i}[e c$ to walk the dog].

b. John's brother ${ }_{i}$ tried [ec to walk the dog]
OBJECT CONTROL SINGLE-COMPLEMENT SUBJECT CONTROL 
186 These two sub-types of obligatory control are produced by children as young as three years of age but at five, children still alternate at the level of chance between subjectand object-oriented interpretations of object control, indicating acquisition is not yet complete (see Kirby, Davies and Dubinsky, 2010b for a recent review of the acquisition literature). Studies have also shown that young children will look beyond the sentential arguments when assigning a referent to the $e c$ in obligatorily-controlled complements.

192 McDaniel, Cairns and Hsu (1990/1), for example, identified a group of children between the ages of $3 ; 9$ and $5 ; 4$ who permitted an arbitrary interpretation of the ec in object-control structures. ${ }^{6}$ Of further interest is that given the appropriate discourse environments, children appear not to stop at arbitrary referents. Some five-year-old children, for example, have been found to bypass the obligatory syntactic antecedent for the $e c$ in obligatory control environments in favour of a sentence-external referent

198 if that referent has been mentioned in the preceding discourse (Eisenberg and Cairns, 1994). This was more prevalent in structures with one main-clause argument (Grover, in a) rather than two (Big Bird and Ernie, in b).

201

(3) a. Grover decides [ec to pat Big Bird].

b. Big Bird tells Ernie [ecto jump over the fence].

202

203 From these works, we can see that reflexives and obligatory control do not develop absolutely in tandem. Control appears to lag a little behind. If we pay attention to what distinguishes these constructions, too, we can see why control might provide a greater learning challenge. A reflexive is always a direct argument of a transitive verb. In this configuration it is strictly anaphoric so its interpretation is entirely predictable once this structural requirement has been grasped. In obligatory control, however, a child needs to determine which verbs, out of a set of transitive verbs, select for controlled complements (see C Chomsky, 1969; Cohen Sherman and Lust, 1993; Guasti, 2004).

211 A further complication is that a verb the child has encountered as an obligatory-control

212 verb in one instance can also occur with a different kind of complement, where the

\footnotetext{
${ }^{6}$ The reader is referred to the original paper (especially pages 302-306 and 323) for the authors' justifications for why the children's interpretations were classified as arbitrary rather than specific external ones.
} 
213 relation is not obligatory control, in another (see Goodluck et al. 2001 for a discussion

214 of this issue in Greek and Spanish children). This can be seen in (4a), which shows a

215 prototypical control verb (tell) with its controlled complement, whose ec carries the

216 object-oriented interpretation. Yet that same verb can combine with a clause which

217 has a verbal gerund subject, whose $e c$ is not restricted in the same way (4b). The $e c$

218 in this type of construction can host a number of interpretations, including sentence-

219 external ones, under the appropriate discourse conditions (see Bresnan, 1982; Janke,

220 2007; Janke and Perovic, accepted).

a. Peter told Johni $\left[\mathrm{ec}_{\mathrm{i}}\right.$ to read the book].

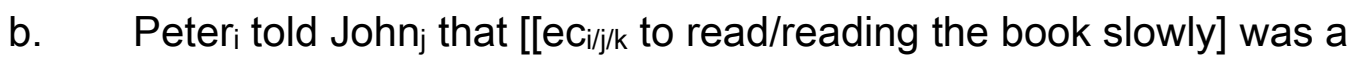
mistake].

This alternative possibility opens up a further learning task for the child. Obligatory control is a member of a wider set of control relations, whose understood subjects differ in terms of how their interpretations are secured. Within obligatory control, they conform to a set of structural requirements, and when these are met, their interpretations are predictable (c.f. 'promise', which we discuss below). But there is also a class of control constructions which is not obligatory. In these instances, the reference of the understood subjects can be discourse determined, as in (4b and 5) or arbitrary, as in (6).

A: The headmaster phoned.

A: He said [ect to introduce yourself $f_{i}$ to the class before he arrives]

(6) A: Did you lock the door?

(Janke, 2007:181, no 65)

Unlike obligatory control, these non-obligatory-control structures are open to pragmatic manipulation. Interpretations are decided on the basis of a contextual cue, as shown by Bresnan (1982) for controlled verbal-gerund subjects. 
(7) Tom ${ }_{i}$ felt sheepish. [ec $i$ Pinching those elephants was foolish].

As the topic of the sentence preceding the non-finite clause, 'Tom' provides the pragmatic lead to the ec's reference (see also Reinhart, 1981, and Samek-Lodovici, 1996). The flexibility in terms of referent choice for non-obligatory control relates back to what is observed in early research on its obligatory counterpart (as in Eisenberg and Cairns above). The five-year-olds who permit sentence-external readings seem to have a wider set of constructions from which to narrow down to obligatory control and they haven't yet reached an adult grammar in which obligatory control is resilient to pragmatic interference. Once the structure of a controlled clause is built, the ecmust receive a specification. If selected by a control verb, this will come from a designated argument in the main clause but if not, the value attributed to it can be arbitrary (where the value is minimal, such as +animate; see Haegeman, 1994) or become specific, given the right discourse conditions (see Ariel, 1988, 2000). The greater number of interpretative possibilities in control suggests an extra level of complexity in the learning task for obligatory control than that which exists for reflexive binding.

The last sub-type of control that is relevant to our current study is rather different from the regular examples of obligatory control shown in ( $2 a$ and b) above, and notorious for the difficulty it causes in acquisition. This is double-complement subject control, represented almost exclusively by the verb 'promise'. In this construction, the locality principle otherwise strictly adhered to (see Rosenbaum, 1967) is broken and the child must work out that for this rogue sentence, the object is skipped in favour of the subject:

(8) John 1 promised Peter 2 [ecito walk the dog]

\section{DOUBLE-COMPLEMENT SUBJECT CONTROL}

There is, as demonstrated in Cohen Sherman and Lust (1986), a conflict between the lexical and structural principles associated with 'promise', principles which need to be reconciled for acquisition to occur. The lexical subject-control property of 'promise' 
contradicts the unmarked structural requirement in double-complement control structures, namely that the closest c-commanding DP in the matrix clause be the antecedent. In contrast, in object control, the lexical and structural requirements tally with one another.

As expected on the basis of its idiosyncratic nature, and its breaking of an already acquired principle, the promise construction is acquired late. Children up to the age of ten can still falter on this example of control (see C Chomsky, 1969; Tavakolian, 1978; Pinker, 1984; Hsu et al. 1989; Eisenberg and Cairns, 1994; Kirby et al. 2010).

\subsection{The Current Study}

291 If we use the literature on binding and obligatory control in TD as a benchmark against which to measure our HFA children's progress, we can form some expectations with regard to their performance in the current study.

We have seen that performance on binding in ASD is mixed. The picture emerging is that children classified as LFA do exhibit problems in this area of grammar, however, HFA children perform on par with their non-verbal MA-matched peers. Following this literature, we expect that our HFA participants will exhibit a level of comprehension of reflexives and pronouns no different to that of their matched controls. Our ability to replicate the aforementioned results on pronouns is particularly important, given the pragmatic deficits for which this population is renowned.

The literature on the acquisition of binding and control in TD has also shown that reflexive binding is achieved before obligatory control. Specifically, for a short time, children continue to accept an incorrect reference in obligatory control after the age at which they perform flawlessly on reflexive binding. If our HFA children are following a typical trajectory, we expect their performance on reflexive binding and obligatory control to exhibit this same order, namely reflexives prior to obligatory control, or rather, an equal pattern of performance, if they are of an age when both of these constructions are already established in typical development. A pattern that deviates 
311 from this order would be one where the HFA children perform worse on reflexives than

312 on obligatory control.

313 Our expectations with regard to performance on obligatory control are more 314 exploratory since there is no work on this construction in ASD yet. We focus on single315 complement subject control (e.g. try), object control (e.g. persuade) and double316 complement subject control (e.g. promise). The single-complement subject control 317 condition, which is the type of control acquired earliest in TD, will indicate whether 318 children show any propensity to opt for a sentence-external, yet pictorially 319 represented, referent. This task would indicate whether a purely visual distraction of 320 an additional potential referent could lead children away from the obligatory 321 antecedent. For object control, we aim to establish if the children adhere to locality, by 322 disallowing a subject interpretation. Lastly, on the basis of the hypothesis that control 323 is not derived by movement, the children's performance on regular control is expected 324 to be far better than that reported in the HFA literature for structures whose underlying movement operation is uncontroversial, namely passives and raising. For doublecomplement subject control our question is whether HFA children exhibit similar problems to those witnessed in much younger TD children with respect to its breaking of locality (C Chomsky, 1969; Tavakolian 1978; Cohen Sherman and Lust, 1993). In light of what is known about the course of development of control constructions in TD children, we would like to see if our HFA children's performance suggests that same course, namely: single-complement subject control < object control < doublecomplement subject control.

334 It is possible that the complex learning task of acquiring different types of control constructions be affected by factors such as chronological age and general linguistic and cognitive skills, thus we shall also investigate the effects of these factors in the performance of our samples. This pertains especially to double-complement subject control constructions, whose tokens are rare and whose acquisition requires a resolution of opposing syntactic and lexical requirements. The same possibility extends to pronouns, which are subject to both syntactic and pragmatic constraints and whose acquisition is also delayed in typical development. 
344 2. Method

\section{$345 \quad 2.1 \quad$ Participants}

346 Seventy-five ${ }^{7}$ children took part in the study: twenty-six HFA children (4 girls) aged 347 between $7 ; 3-16 ; 4(M=12 ; 02, S D=2 ; 06)$ were matched individually to one group of 348 twenty-four ${ }^{8}$ TD controls (5 girls), aged 6;06-15 ( $\left.M=9 ; 09, \mathrm{SD}=2 ; 04\right)$ on non-verbal 349 reasoning, and matched individually to another group of twenty-five ${ }^{9}$ TD control 350 children (4 girls), aged 5;06-13;01 ( $M=8 ; 09, S D=2 ; 04)$ on verbal MA.

HFA children were recruited from four specialist schools for children with ASD in greater London, Berkshire and Kent. The clinical diagnosis of ASD ${ }^{10}$, a key entry requirement to the school, was made on the basis of either DSM-IV TR (APA, 2000) or ICD-10 (WHO, 1992). None of the children had any hearing impairments or any accompanying deficits (neurological or genetic disorder, such as Rett syndrome, tuberous scleroris, fragile X). Details of the participants' ages and scores on measures of verbal and non-verbal abilities are given in Table 1. Their non-verbal IQ, as measured on the Matrices subtest of the Kaufman Brief Intelligence Test (KBIT) ranged between 82-154, $M=113.65$ ( $S D=15.64)$. Following the standard literature on HFA classifications, only children whose non-verbal IQ was 80 or above were included. Their scores on standardized tests of verbal abilities were rather heterogeneous, in line with the literature (e.g. Kjelgaard and Tager-Flusberg 2001): on the British Picture Vocabulary Scales II (BPVS II), their standard scores ranged from 45 to $121, M=90.77$ (SD=23.87), and on the Test of Reception of Grammar 2 (TROG) from 55 to $116, M=91.73$ (SD=18.33). ${ }^{11}$ TD controls, with no known developmental

\footnotetext{
${ }^{7}$ Two more HFA children were recruited but were excluded from this number for failing to complete the test battery.

8 This group consists of 24 participants, as no suitable matches could be found for two HFA children who gained extremely high raw scores on KBIT ( 44 and 48 out of the possible 48 ).

9 This group consists of 25 participants, as no suitable match could be found for one HFA child with a low raw BPVS score (45).

${ }^{10}$ One of the children had a diagnosis of Asperger syndrome rather than ASD, but since Asperger has been subsumed under the general ASD diagnoses in the latest version of DSM-5, it was decided to collapse both diagnoses in this sample.

11 Despite the wide range of children's standard scores on the tests of grammar (TROG 2) and vocabulary (BPVS II), only three children in our sample could be classified confidently as Autism plus
} 
367 delays or hearing impairment, were recruited from schools in greater London and

368 Berkshire. One group of children, TD KBIT, was matched individually to the HFA

369 children on non-verbal reasoning, as per the raw score on KBIT Matrices, as well as

370 gender. The other control group, TD BPVS, was matched individually to the HFA

371 children on verbal MA, as per the raw score on BPVS 2, and gender. Twelve adult

372 controls from the same geographical regions were also recruited. Their performance

373 on the experimental task was at ceiling. ${ }^{12}$

Table 1.1. Ages and Mean Standard and Raw Scores (Standard Deviation) on Tests of Language and Cognition for all Participant Groups.

$\begin{array}{llll}\text { Group } & \text { HFA } & \text { TD KBIT } & \text { TD BPVS } \\ & n=26 & n=24 & n=25 \\ \text { Age in months } & 147.31(31.14) & 119.21(28.77) & 106.92(29.55) \\ \text { Range } & 88-197 & 80-180 & 68-158 \\ \text { KBIT SS } & 113.65(21.09) & 119.58(15.63) & - \\ \text { Range } & 82-154 & 88-158 & \\ \text { KBIT Raw Scores } & 33.96(7.04) & 32.08(6.13) & - \\ \text { Range } & 22-48 & 21-44 & \\ \text { BPVS-II SS } & 90.77(23.87) & - & 115.92(13.99) \\ \text { Range } & 45-121 & & 97-149 \\ \text { BPVS-II Raw Scores } & 100.69(23.69) & - & 102.44(21.21) \\ \text { Range } & 45-137 & & 61-141 \\ \text { TROG-2 SS } & 91.73(18.34) & - & - \\ \text { Range } & 55-116 & & \end{array}$

Language Impairment (ALI), having scored at/or nearly at floor on these measures. Their BPVS standard scores were 45 and 47 and their scores on TROG were 53 and 55 . A further child could be classified as borderline impaired (Kjelgaard and Tager-Flusberg, 2001) on both measures: 79 on BPVS and 78 on TROG, while two more scored in the severely impaired range on the vocabulary measure (BPVS SS of 54 and 55) but not the grammar measure (TROG SS of 79 and 81). These were not classified as ALI.

12 In some dialects of American English, promise, although always carrying a subject-reading, is a more marked construction. For this reason it was important that our adult participants' interpretations all converged, in their universally accepting the construction and rejecting an object reading. 
TROG-2 Raw scores $14.69(4.44)$

Range 4-20

378 Key: KBIT SS = Kaufmann Brief Intelligence Test Standard Scores; BPVS SS = British

379 Vocabulary Scales Standard Scores; TROG SS = Test of Reception of Grammar

380 Standard Scores. Measures on which HFA participants are matched to TD controls 381 are in bold.

382

$383 \quad 2.2$ Materials

384 2.2.1 Binding Task

385 To test children's comprehension of binding, we employed a two-choice picture386 selection task from Perovic and Wexler (2007) and Perovic et al. (2013a, b), who used

387 it on a large number of typical children and children with developmental disorders such

388 as ASD and Williams syndrome. The pictures, which involved the well-known 389 characters from the Simpson family, were presented on a laptop screen (specific 390 details about the procedure are given at the end of the Methods section, as they 391 pertain to both the Binding and Control tasks).

392 The task included two critical conditions, Name Reflexive and Name Pronoun, and two 393 control conditions, Name Possessive and Name Name. In Name Reflexive and Name 394 Pronoun, the subject of the sentence was always a possessive noun phrase (e.g. 395 Bart's dad) and the object was either a reflexive (e.g. himself) or a pronoun (e.g. him). 396 Thus the Name Reflexive sentence 'Bart's dad is washing himself' was presented with 397 two pictures on the screen: one picture in which Homer (Bart's dad) is washing himself 398 in a bathtub with Bart standing by (the correct choice), and the other picture in which 399 Homer is washing Bart who is sitting in a bathtub (the incorrect choice). The Name 400 Pronoun sentence 'Bart's dad is washing him' was presented with one picture showing 401 Homer washing Bart who is sitting in the bathtub (the correct choice), and the other 402 picture showing Homer washing himself in a bathtub with Bart standing by (incorrect 403 choice).

404 Possessive noun phrases as subjects provided two possible antecedents for the 405 reflexive or pronoun: Bart's dad (i.e. Homer), which c-commands the object, and Bart, 406 the possessor, which does not. In order to independently test participants' 
understanding of possessive noun phrases, and the crucial relation of c-command, the control condition Name Possessive also used a possessive subject (Bart's dad). For a sentence 'Bart's dad is eating an ice cream', one picture showed Homer (Bart's dad) eating an ice cream (correct choice), and the other picture showed Bart eating an ice cream (incorrect choice).

412 Name-Name also served as a control condition, containing proper names in the

413 subject position and no reflexives or pronouns in the object position (e.g. 'Bart is 414 washing dad), in order to test that the child could understand the task.

415 Four verbs, 'wash', 'touch', 'point to', and 'dress' were used in the NP and NR 416 conditions, with each verb occurring twice. Each of the four conditions included eight sentences, giving a total number of 32 sentences in the task.

\subsubsection{Obligatory Control Task}

A new two-choice picture-selection task using the same Simpsons characters as above was devised for the following control constructions: single-complement subject control (try), object control (persuade) and double-complement subject control (promise). ${ }^{13} \mathrm{~A}$ simple SVO structure was used to test that the children understood the task. All sentence types included eight items. ${ }^{14}$

426 Prior to the trial, we used a structured interview technique to determine the children's understanding of the verbs independently of control. The specific questions that each child was asked, together with a representative selection of the children's responses can be found in Appendix D. Only one child with HFA gave a less than satisfactory answer on try, however, it was decided not to exclude him as his performance on this condition was at ceiling.

433 The following sentence types and corresponding pictures were used in the Control task:

\footnotetext{
${ }^{13}$ These verbs were chosen because they represent prototypical examples of control but also because they lent themselves well to the task adopted here.

14 Two additional tasks, testing the adjuncts 'while' and 'after' were also included in the test battery but their results are not included in the current analysis.
} 
435 Single Complement Subject Control (try): Four of the eight sentences in this condition

436 included the main-clause subject performing an action on the complement's inanimate

437 object with another unmentioned character depicted nearby. To illustrate, the sentence

438 'Bart tried to eat the sandwich' was accompanied by a corresponding picture in which

439 Bart was eating a sandwich while Lisa stood next to him, and a foil in which Lisa was

440 eating the sandwich and Bart stood next to her. This tested whether the child would

441 opt for a visually depicted yet unmentioned referent as the agent of 'eat' (Lisa in this

442 instance) over the visually depicted sentence-internal referent. The other four

443 sentences included the main-clause subject performing an action on the complement's

444 animate object. Thus 'Homer tried to wash Bart' was accompanied by a corresponding

445 picture in which Homer was washing Bart, and a foil in which Bart was washing Homer.

446 This checked whether the child might choose an incorrect referent on the basis of a

447 'last-heard referent' strategy. ${ }^{15}$

448 Object Control (persuade): This condition used corresponding pictures in which the 449 matrix object engaged in an action. The foil pictures depicted the matrix subject

450 engaging in the action. For the example sentence 'Homer persuaded Marge to drive 451 the car', the corresponding picture showed Marge driving, with Homer standing next 452 to the car, whereas in the foil, Homer was behind the wheel with Marge standing by.

453 Double Complement Subject Control (promise): The corresponding pictures showed the matrix subject engaged in an action, whereas in the foils the matrix object was the actor. In the example sentence, 'Homer promised Marge to walk the dog', the correct picture depicted Homer leading the dog with Marge standing by, whereas in the foil Marge led the dog and Homer stood next to her. ${ }^{16}$

458 Serving as a control condition to test that the participants could understand the task, 459 the SVO condition contained simple subject-verb-object sentences with no embedding

\footnotetext{
15 These two sets of sentences were originally treated as two sub-conditions: try-animate and tryinanimate, however, no difference was found in the children's performance and the responses were analysed together.

16 Note that the main verbs in all of the above conditions were in the past tense. Following a pilot study in present tense with several children and adults, it was agreed that past tense best suited the promise sentences. To reduce variation between conditions, all of the verbs in the three experimental conditions were changed to past tense. The last version of the task was administered to the twelve adults, aged 18-55, all of whom demonstrated ceiling performance.
} 
and no infinitive verbs. They included the same characters and similar types of action to the other pictures, for example, the sentence 'Homer is walking the dog' was accompanied by two pictures, one showing Homer walking the dog with Marge looking on, and a foil in which the characters were reversed.

As can be observed in Appendix B, the sentences included a variety of actions, in order to keep the pictures and the task more engaging. The verbs were used at most twice in each of the conditions.

467

\subsection{Procedure}

469 Both Binding and the Control tasks involved an identical procedure. Participants were shown pictures on the laptop computer, and then asked to point to the picture that went best with the sentence they heard ('Point to the picture that goes best with what I say'). The instructions were given for the first and second trial, after which children continued to respond without further instructions. Each participant was presented with a different order of pictures, which was randomized automatically by the software used. The location of the correct picture (i.e. whether it occurred on the right or left) was balanced throughout.

477 Prior to the administration of each task, children were familiarized with the characters and the actions depicting the verbs used in the tasks (see Appendix C).

479 The test battery was administered in a quiet room at the children's schools by one of the two experimenters present in the room. The battery was presented over the course of two sessions, each lasting approximately 30 minutes. To keep the length of each session similar, the order of presentation was BPVS, KBIT and the Binding task in the first session, and TROG and the Control task in the second session. There was a space of 2-3 weeks between sessions. The scoring of the binding and control tasks was computerized, i.e. the software recorded the picture choice, while the standardized tests were scored by the experimenter administering the test on a scoring sheet. Aside from being presented on the screen, the sentences were uttered by the experimenter once. The children were free to ask for the sentence to be repeated if necessary and were not penalized if the sentence was repeated.

\section{Results}


493 Participants' responses to each item (correct or incorrect) were analysed using the

494 GLMM procedure in SPSS, 21, as logistic regression models have been argued to be 495 better suited to binomially distributed data than ANOVAs (Jaeger 2008; Quene and 496 van der Bergh, 2008). The fixed effects built into the model were Group, Sentence 497 Type and the Group*Sentence Type interaction. Separate analyses were carried out 498 for the two tasks.

499

\section{$500 \quad 3.1 \quad$ Binding}

501 Table 1.2 shows estimated mean probabilities correct and the standard error for each sentence type. The analysis revealed no significant effect of $\operatorname{Group}(F(2,288)=0.223$, $\mathrm{p}=.801)$ but a significant effect of Sentence Type $(F(3,288)=14.793, p<.001)$. No significant Group*Sentence Type interaction was found $(F(6,288)=0.999, p=.426)$.

Table 1.2 Estimated Mean Probabilities Correct (Standard Error) on Binding 508

\section{Sentence}

Name Pronoun

Name Reflexive

Name Poss.

Name Name
HFA

\section{Mean}

0.90

0.94

0.99

0.99
TD KBIT

\section{SE}

(0.04)

(0.01) $\quad 0.99$

(0.01) $\quad 0.98$

\section{Mean}

0.89

0.98

(0.04)

$(0.01)$

$(0.01)$

(0.01)
TD BPVS

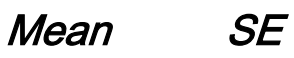

0.89

0.99

0.99

0.98

Note: HFA=high-functioning autism group, TD KBIT=typically developing group matched on raw score of KBIT, TD BPVS= typically developing group matched on raw score of BPVS.

512

513 Pair-wise comparisons (Sidak-corrected) uncovered no difference between groups on

514 any of the conditions. As indicated by the significant effect of Sentence Type, for all 515 groups collapsed, children performed better on all sentence types than on the Name-

516 Pronoun condition: Name-Reflexive $(\mathrm{t}(288)=3.606, \mathrm{p}=.001) \quad(\mathrm{OR}=6.93)$, Name-

517 Possessive $(\mathrm{t}(288)=4.465, \mathrm{p}<.001) \quad(\mathrm{OR}=19.85)$ and Name-Name $(\mathrm{t}(288)=4.191$, $518 \mathrm{p}<.001)(\mathrm{OR}=10.77)$. The groups' performance did not differ on other conditions: 519 Name-Possessive vs. Name-Name $(\mathrm{t}(288)=.908, \quad \mathrm{p}=.722$ (OR=1.84), Name- 
520 Possessive vs. Name-Reflexive $(\mathrm{t}(288)=.941, \mathrm{p}=.722(\mathrm{OR}=2.86)$ and Name-Name vs.

521 Name-Reflexive $(\mathrm{t}(288)=.474, \mathrm{p}=.722$, $(\mathrm{OR}=1.55)$. In contrast to the uniformly ceiling

522 performance on the other three sentence types, the individual data in the Name-

523 Pronoun condition shows variation in all of the groups (see scatterplot in Figure 1),

524 particularly in the youngest TD BPVS group and the HFA group.

526 Figure 1: Scatter plot showing the relationship between age (x-axis) and children's 527 performance on Name-Pronoun (y-axis).

528

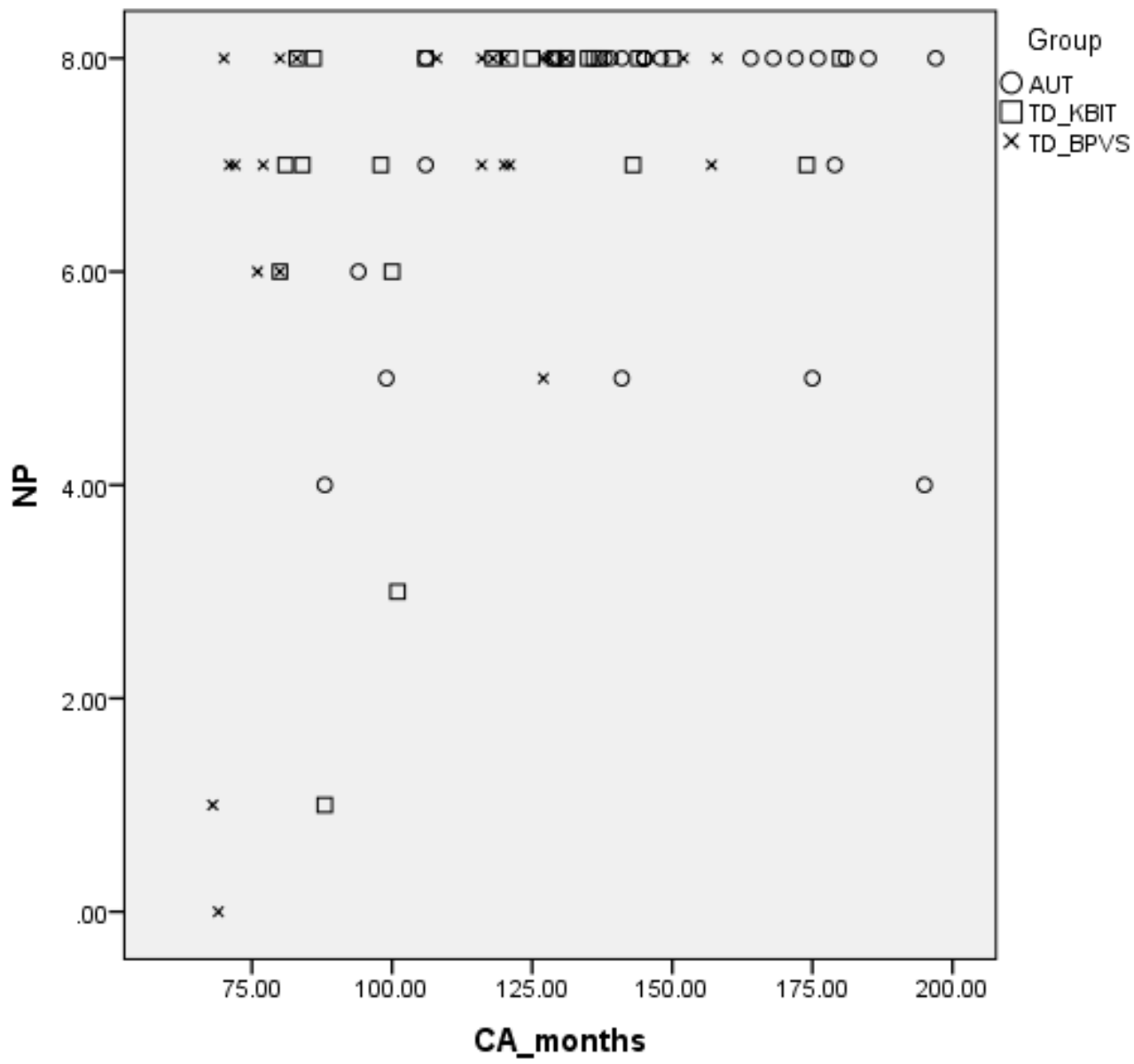

531 The Name-Reflexive condition also elicited a consistent ceiling performance from the

532 TD groups, although three HFA children scored at or below chance ${ }^{17}$ on this condition.

533 Individual variability in the groups' performance is shown in the scatterplot in Figure 2.

534 It is worth noting here that two of these children qualify as ALI (their score on Name-

17 We consider the score of 6 out of $8,75 \%$, to be above chance. 
535 Reflexive were $1 / 8$ and $3 / 8$ correct), while one child who scored $6 / 8$ correct was 536 borderline ALI (see footnote 11).

537

538 Figure 2: Scatter plot showing the relationship between age (x-axis) and children's performance on Name-Reflexive (y-axis).

540

541

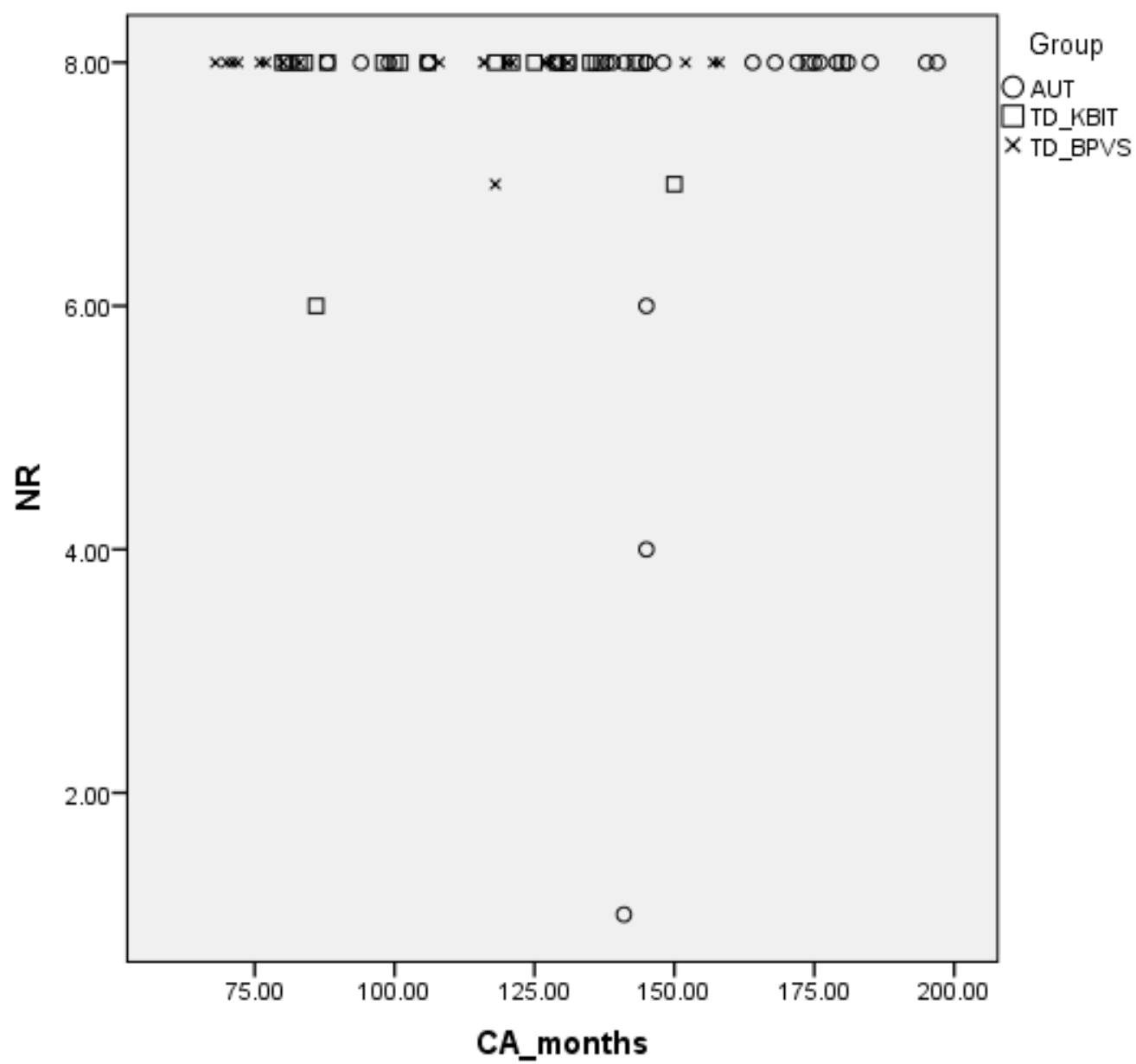

$544 \quad 3.2$ Obligatory Control

545 The analysis revealed no significant effect of $\operatorname{Group}(F(2,288)=2.078, \mathrm{p}=.127)$, again

546 a highly significant effect of Sentence Type $(F(3,288)=18.540, \mathrm{p}<.001)$ and no

547 significant Group*Sentence Type interaction $(F(6,288)=1.192, \mathrm{p}=.310)$. Estimated

548 mean probabilities correct and the standard error for each sentence type are given in 549 Table 1.3. 


\begin{tabular}{llclllll} 
Sentence & HFA & & TD KBIT & \multicolumn{3}{c}{ TD BPVS } \\
& Mean & SE & Mean & SE & Mean & SE \\
Promise & 0.70 & $(0.06)$ & 0.92 & $(0.04)$ & 0.77 & $(0.05)$ \\
Tryi8 & 0.99 & $(0.01)$ & 0.98 & $(0.01)$ & 0.96 & $(0.01)$ \\
Persuade & 0.96 & $(0.02)$ & 0.94 & $(0.03)$ & 0.95 & $(0.03)$ \\
SVO & 0.99 & $(0.01)$ & 0.99 & $(0.01)$ & 0.97 & $(0.01)$
\end{tabular}

553

554 The significant effect of Sentence Type for all groups when collapsed was sourced to 555 their performance on promise. Sidak-corrected pair-wise comparisons revealed that 556 the TD KBIT group performed significantly better on promise than the HFA group $557(\mathrm{t}(288)=3.110, \mathrm{p}=.006)(\mathrm{OR}=4.93)$, and marginally better than the TD BPVS group $558((\mathrm{t}(288)=2.157, \mathrm{p}=.063)(\mathrm{OR}=3.43)$. There were no differences in the performance of 559 the HFA group and the younger TD BPVS $(\mathrm{t}(288)=0.915, \mathrm{p}=.361)(\mathrm{OR}=1.43)$.

561 There were no statistically significant differences in the performance of the three 562 groups on any of the remaining sentence types (estimated mean probabilities correct 563 were between .94 and .99 for all groups):

564 - try - HFA vs. TD KBIT: $(\mathrm{t}(288)=0.090, \mathrm{p}=.928)(\mathrm{OR}=2.02)$, TD KBIT vs TD 565 BPVS: $(\mathrm{t}(288)=1.348, \mathrm{p}=.384)(\mathrm{OR}=2.04)$, HFA vs. TD BPVS: $(\mathrm{t}(288)=1.446$, $p=.384)(\mathrm{OR}=4.12)$; BPVS: $(t(288)=0.170, p=.954)(O R=0.82)$, HFA vs. TD BPVS: $(t(288)=0.300$, $p=.954)(\mathrm{OR}=1.26)$

\footnotetext{
18 Note that there were two out of 85 children who made two errors on try (all other children made no errors, or one error only in the animate or inanimate sub-condition). The children who did make two errors were a HFA child, whose extremely low vocabulary and grammar scores indicated a clear language impairment, and one young typical child, aged $6 ; 6$. Their errors concerned only the animate sub-condition, which suggests that animacy may have played a role in the comprehension of try sentences in these two children.
} 
574 Figure 3: Scatter plot showing the relationship between age (x-axis) and children's 575 576

- SVO - HFA vs. TD KBIT: $(\mathrm{t}(288)=0.429, \mathrm{p}=.668)(\mathrm{OR}=1)$, TD KBIT vs TD BPVS: performance on promise (y-axis).

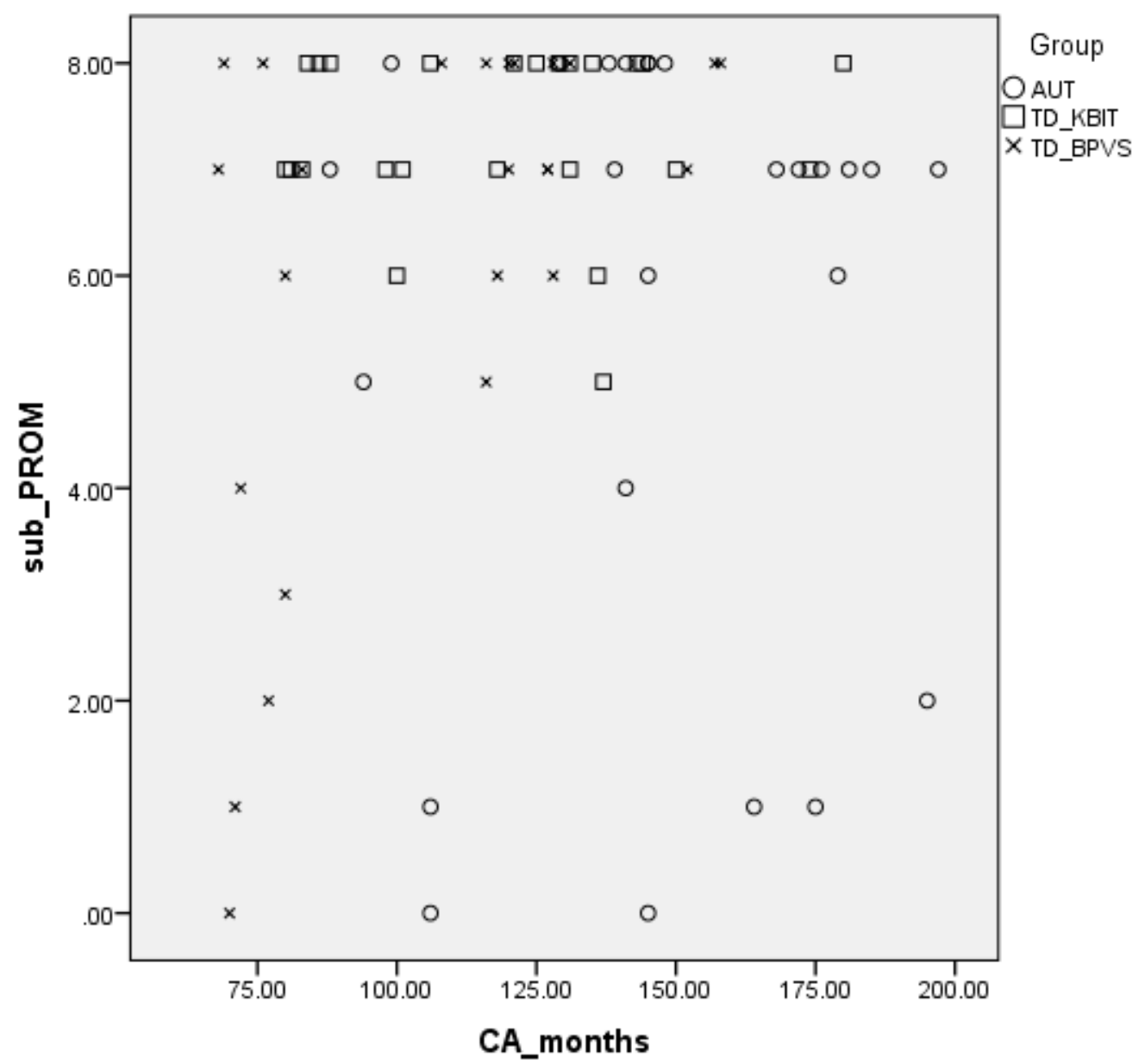

579 In the HFA group, eight children had significant difficulties interpreting promise (5 and 580 less out of 8 correct), compared to six children in the TD BPVS group, and one child 581 in the TD KBIT group (see scatter plot in Figure 3).

583 All incorrect responses on promise were examined to check whether difficulties could 584 be sourced to occurrences of particular verbs, e.g. that the verb 'walk' was used twice 585 in this condition, rather than once. This was not the case in any of the groups. 


\subsection{Correlation Analyses}

588 In order to ascertain the influence of age and general verbal and non-verbal abilities on the accuracy of children's comprehension of the two sentence types which showed most variation, promise and Name-Pronoun, we ran three correlation analyses. Our findings show that age was positively correlated to performance on the Name-Pronoun and promise conditions only in the youngest TD BPVS group but not in the HFA group, or the TD KBIT group (see earlier scatterplots for a clearer view of the relationship between age and children's performance on relevant sentence types). Performance on KBIT (measuring non-verbal reasoning), BPVS (measuring receptive vocabulary) and TROG (measuring receptive grammar) was positively correlated to the HFA group's performance only on promise, but not on Name-Pronoun. The performance of the two typical groups on Name-Pronoun and promise was not correlated to their performance on KBIT or BPVS19.

600

601

Table 3: Pearson correlation coefficients of the relationship between children's scores on Name-Pronoun (NP) and promise (out of 8 possible correct), and age, non-verbal reasoning (standard scores on $\mathrm{KBIT}$ ), receptive vocabulary (standard scores on BPVS) and grammar (standard scores on TROG).

605

$\begin{array}{lllllll} & \text { HFA } & & \text { TD KBIT } & & \text { TD BPVS } \\ & \text { NP } & \text { promise } & \text { NP } & \text { promise } & \text { NP } & \text { promise } \\ \text { Age } & .226 & .018 & .387 & .015 & .439^{*} & .549^{* *} \\ \text { KBIT SS } & .247 & .447^{*} & .208 & .073 & .370 & .091 \\ \text { BPVS SS } & .175 & .474^{*} & -.246 & .148 & -.003 & .060 \\ \text { TROG SS } & .361 & .472^{*} & - & - & - & -\end{array}$

606

607

608

609

4. Discussion

\footnotetext{
19 The negative correlation coefficient between BPVS and Name-Pronoun in both TD groups was due to several younger children with very high BPVS SS, who scored low on Name-Pronoun due to their young age.
} 
610 The present study drew a comparison between comprehension of reflexive binding 611 and obligatory control in twenty-six British high-functioning children with autism and 612 two groups of TD children, individually matched on verbal and non-verbal abilities. The 613 choice of these two constructions was motivated by both clinical and theoretical 614 considerations. Its clinical import is that of contributing to the as yet still limited 615 literature on complex syntax in ASD. Obligatory control has not been studied at all in 616 this population and reflexive and pronominal binding only to a limited degree. Of 617 theoretical interest is whether the mechanism underlying control is the same or 618 different to other constructions that have been traditionally argued to involve the same 619 underlying syntactic mechanisms, such as raising. Specifically, if control is a 620 dependency involving a relation between a trace and an antecedent, we expected our 621 HFA children to exhibit difficulty with it on a par with that found for raising and passives. 622 If not movement-based, however, we expected it to pattern more closely to the results 623 found for binding. We found the latter to be true. The two sentence types that did cause 624 difficulty, and showed most variation in the groups' performance, were pronominal binding (the Name-Pronoun condition), and particularly double-complement subject control (the promise condition). We start our discussion with binding, indicating how 627 the current results map with the previous literature, and then move onto control, 628 drawing a distinction between the three different sub-types and the contributions that the current disclosed patterns provide for our understanding of the HFA grammatical profile and for our more general understanding of the nature of the control relation.

As a group, the HFA children showed a very good comprehension of reflexives, with an estimated mean proportion correct of .94, suggesting intact reflexive binding. These results on British children tally precisely with those found for American HFA children's comprehension of reflexives as reported in Perovic et al. (2013a). Three children in the current sample of twenty-six showed less than perfect performance: two performed at or below chance on this sentence type, and one just above chance. Crucially, the first two children qualified as ALI ('autism plus language impairment') and the third as a border-line $\mathrm{ALI}$, as per their scores on the standardized language assessments. This 640 is again in line with Perovic et al. (2013b), whose sample of twenty-six ALI children also showed a chance performance on reflexives, which was interpreted as signaling deficient knowledge of reflexive binding. However, some variability in the performance 
643 of children with ALI is also noted here: one child classified as ALI showed a ceiling

644 performance on reflexives.

646 No difference between the three groups was observed in the pronoun condition. The 647 estimated mean proportion correct in HFA was .90, and in the two TD groups it was 648 .89. Although this is a high performance, notable variation is still evident in all three 649 groups. The variation we see in our current samples is also in line with the previous 650 literature. In Perovic et al. (2013b), twenty-two children classified as ALN ('autism with normal language'), exhibited some difficulties in their interpretation of pronouns in an identical task, although again, their performance did not differ from a group of nonverbal MA-matched controls.

The literature on typical development reviewed in earlier sections reports that the problems with pronoun interpretation disappear with age. This age-dependent development is corroborated in our TD sample (especially in the younger TD BPVS group), but not in our HFA group. Both age and scores on the standardized assessments of non-verbal reasoning, vocabulary and syntax comprehension varied greatly in our HFA participants, but none of these correlated with their performance on pronouns. If we assume that there are variable levels of difficulty with pragmatics in our sample, and if the interpretation of pronouns is decided at the syntax-pragmatics interface, then the absence of any correlations on these measures is perhaps expected.

666 For the obligatory control conditions, the simplest construction tested was singlecomplement subject control (try). Incorrect answers would either have indicated that the children permitted free interpretation of the implicit agent (where the direct object in the infinitival was inanimate) or that they were employing a last-heard referent strategy (where the direct object in the infinitival was animate). Ceiling performance on this construction confirmed that this was not so. With regard to object control (persuade), there was also no difference between groups. As a first test on knowledge

673 of this construction in HFA children, the results from these two regular examples of 674 control offer support for the claim that the syntax underlying canonical obligatory control is preserved. The children's systematic preference for an adult-like reading 
676 points to a firm grasp of the obligatory nature of the interpretative link between the argument in the main clause and the understood subject in the complement.

We turn now to double-complement subject control (promise) for which there was a varied performance, especially in the HFA children and their language-matched control group with estimated mean probabilities correct of .70 and .77, respectively. First of all, our finding supports all the studies that have tracked this construction's development in TD children (e.g. Hsu et al. 1989; Cohen Sherman and Lust, 1993; Eisenberg and Cairns, 1994). The promise sentences proved exceptionally difficult for only a proportion of our HFA group. However, eighteen children demonstrated an adult-like grasp of this construction. Let us look more closely at the eight who did not. A first possibility we need to exclude is that they were not paying attention to the whole sentence string. If the children attended only to the final part of the sentence, then their poor performance is orthogonal to the control properties of this particular verb. ${ }^{20}$ This would explain their choosing the object in the persuade and the promise constructions, since the picture fits with the main-clause object in both, as indicated by the underlining in the examples below:

(a) Homer persuaded Marge to hold the dog

Lack of attention to the main-clause verb, however, would predict that the children who performed poorly on promise opted for the object in both persuade and promise uniformly, which is true only for one of the twenty-six children. The other twenty-five succeeded with persuade but gave mixed responses for promise; this equates with a stage of development for this construction suggested in much previous work on younger TD children (see references above).

Another possibility that needs to be ruled out is that it is the meaning of the verbs used in these control examples which is responsible for these children's poor performance on promise. If so, this again would be independent of any syntactic source to the

20 We thank Nina Hyams for alerting us to this possibility. 
707 problem. It is well known, for example, that individuals with ASD have an impaired 708 ability to mentalise (Happé, 1993), and the obligatory-control verbs used here all 709 involve intentions: try involves an intention on the part of the agent, and persuade and 710 promise both relate to or involve a change in mental states. However, the children 711 demonstrated their understanding of the verbs used in the task prior to the test itself 712 even those children who exhibited very poor comprehension of the promise 713 constructions. Furthermore, problems with verbs relating to intentions cannot account

714 for the discrepancy between the children's perfect performance on try and persuade and the flawed performance on promise, as all three conditions employed these verbtypes. This line of argumentation would also not generalize to children without autism, whose delayed acquisition of the promise construction, and not the meaning of the verb itself (C Chomsky, 1969), is legendary and witnessed once again in the current sample of TD children.

721 The question remains as to what property of the promise construction makes it so difficult for children. The children giving mixed responses on promise appear reluctant

723 to break locality. This could be because of a propensity to avoid long-distance 724 dependencies generally, as reported for A-bar movement in ASD in Zebib et al. (2013) 725 for example. However, we think it more likely that for this particular construction, the 726 problem stems from the exceptional status of this type of control, and from the reconciliation needed between conflicting lexical and syntactic requirements for this construction, which simultaneously demand a subject and an object reference respectively (see references above). There is a large number of object-controlled

730 double-complement structures (e.g. tell; order; force) relative to this one nearly 731 isolated construction which contradicts an otherwise very predictable locality rule. To 732 view the learning problem in this instance as one deriving from a deficit in establishing 733 a long-distance syntactic dependency would be far-fetched in the absence of any other 734 similar constructions against which to test. The handful of other examples of subject735 controlled double complements involve verbs that are highly infrequent and/or have 736 other complications (e.g. threaten; guarantee; vow to - see Boeckx and Hornstein, 737 2004), making them a poor means for comparison. Furthermore, in their responses, 738 we have seen nothing different from that witnessed in the TD literature for younger 
739 children. ${ }^{21}$ It is also worth highlighting that at the age at which TD children have

740 mastered constructions with long-distance dependencies (see for example C 741 Chomsky, 1969, and de Villiers, Roeper and Vainikka, 1990, and Thornton and Crain, 1994, on long-distance wh-movement) they still falter with promise.

744 It is noteworthy that the HFA children's performance on promise did again not correlate with age. This distinguishes them from the youngest language-matched TD group, where a highly significant age-related correlation for success on promise was observed. This correlation was also not observed in the older TD group matched on non-verbal-reasoning, though their ceiling performance precluded the possibility of seeing such a correlation. However, the HFA group's performance on promise correlated moderately with their performance on the standardized tests of language and non-verbal reasoning, a correlation not observed in either of the TD control groups. Thus it seems that strong vocabulary and syntax comprehension is needed for the above mentioned reconciliation between conflicting lexical and syntactic requirements for this construction. ${ }^{22}$

The design of the current task enables us to return to our earlier discussion of experiments on argument dependencies in autism, which adopted a similar experimental design (Perovic et al. 2013a, b; Perovic and Wexler, 2007), and relate these to the results on regular control and binding found here. Recall that LFA- but not HFA children performed deficiently on binding, whereas children with autism across the low- and high-functioning range seem to show difficulties comprehending passives and raising. Reflexives and the implicit subject in controlled complements require a local, agreeing and c-commanding argument from which they gain their reference.

764 This much they share. On most theoretical accounts, they are also not derived by movement/displacement (see Williams, 1980; Manzini, 1983; Landau, 2000; 2013; Janke, 2007; Rooryck, 2007; but see Hornstein, 2001, for a raising-based account).

\footnotetext{
21 See Caplan and Hildebrandt (1988) for data on two aphasic patients who also show a pattern of better performance on object control, persuade, and a poorer performance on subject control, promise. ${ }^{22}$ An approach that appears promising in terms of facilitating abstract representations of structures that children with SLI find difficult is set out in Garraffa, Coco and Branigan (2015), which used a sentencepriming paradigm effectively.
} 
767 But the two relations cannot be conflated entirely (see also Lasnik, 1992). As mentioned in the introduction, the null subjects in control also form a heterogeneous set in terms of how their reference is determined, encompassing subject, object, discourse, and generic interpretations. In obligatory control, it must be established whether or not a particular verb selects for a controlled complement. If it does, there will be a designated controller and part of the child's learning task is to grasp the obligatory nature of this relationship. This selectional restriction is not operative for the $e c$ in non-obligatory controlled clauses, whose interpretation is regulated extrasyntactically. Depending on the type of control then, namely whether it is an example of obligatory or non-obligatory control, correct interpretation can call upon lexical, syntactic and pragmatic knowledge. This is unlike himself/herself, which, whenever it is the direct argument of a verb, is always an anaphor. If, as we intimated above, acquisition of anaphoric dependencies is a similar yet less complicated learning task to obligatory control, then a natural expectation that arose from this was that our HFA children who succeeded on a picture-selection task on regular control would also succeed on a picture-selection task on reflexive binding. This is exactly what we found.

The results of studies on passives and raising reviewed earlier suggest a different picture for these constructions: problems appear to be evident in children across the spectrum, and, most relevant to our current discussion, to HFA children. If the syntactic principles underlying obligatory control differ from those that regulate passives and raising, in not involving A-movement, then the bifurcation emerging here, with obligatory control and binding on the one hand and passives and raising on the other, makes sense theoretically. As we noted in the introduction, there have been a number of recent studies into populations with ASD, using constructions whose underlying movement is uncontroversial, namely wh-questions (Zebib et al. 2013) and relative clauses (Riches et al. 2010; Durrleman and Zufferey, 2013). An interesting proposition emerging from this discussion is that HFA individuals have adult-like competence of reflexive binding and (regular) obligatory control but not of wh-movement, relative clauses, passives and raising. The relations that seem to cause difficulties involve both A-bar dependencies (relative clauses and wh-movement) and A-dependencies (passives and raising), yet all involve displacement of some kind. The A-bar dependencies that are most problematic are those which employ the greatest number 
800 of movement operations (or constructions involving the most distance between the

801 place in which the argument surfaces and where it is interpreted), making it plausible

802 that HFA children struggle with long-distance dependencies. Yet passives and raising

803 are local relations, which suggests that displacement itself might be sufficient to cause

804 the children difficulty. Future experimentation, perhaps also on more unaccusatives,

805 can help us decide.

806

\section{$807 \quad 5 . \quad$ Conclusions}

808 This paper forms a novel contribution to a line of studies dedicated to the more general 809 question of whether complex grammar is intact in children on the autistic spectrum. It 810 has taken a new example of complex grammar, namely obligatory control, and tested

811 the preferred interpretations of these constructions in HFA children. The children's

812 results on these constructions were compared with that of binding. One important

813 finding is that for regular examples of subject- and object-control and the binding of 814 reflexives, all but three children (who were classified as ALI) achieved a successful 815 performance, a result that lends support to these examples of complex grammar being 816 spared in this population. We have also discussed the degree to which properties of

817 obligatory control and binding differ from other examples of complex grammar, in 818 particular, passives and raising. The current study's results found binding and 819 obligatory control to pattern together: both were unaffected in our HFA children. We 820 contrasted this excellent performance with previous studies on passive and raising, 821 which have reported deficiencies, and suggested that together, these support a 822 distinction in terms of the syntactic operations underlying them. The significant 823 difficulties observed for the promise construction were not restricted to our HFA group, 824 but were also observed at a similar level in the language-matched TD controls. In line 825 with previous literature on this anomalous construction, we attribute their difficulty to 826 its breaking of locality, which is an otherwise robust grammatical principle that children 827 have already acquired and can rely on for its consistency. Children have to abandon 828 this rule for only one construction. Their reluctance to do so translates into 829 compromised acquisition.

830

\section{Appendices}


(2015. This manuscript version is made available under the CC-BY-NC-ND 4.0 license http://creativecommons.org/licenses/by-nc-nd/4.0/

833 Appendix A. Binding Sentences

834

835 1. Name Reflexive

836 Bart's dad is touching himself.

837 Lisa's mum is touching herself.

838 Bart's dad is pointing to himself.

839 Lisa's mum is pointing to herself.

840 Bart's dad is washing himself.

841 Maggie's mum is washing herself.

842 Maggie's mum is dressing herself.

843 Lisa's mum is dressing herself.

845 2. Name Pronoun

846 Bart's dad is touching him.

847 Lisa's mum is touching her.

848 Bart's dad is pointing to him.

849 Lisa's mum is pointing to her.

850 Bart's dad is washing him.

851 Maggie's mum is washing her.

852 Maggie's mum is dressing her.

853 Lisa's mum is dressing her.

855 3. Name Possessive

856 Bart's dad is licking a lamp post.

857 Lisa's mum is waving a flag.

858 Bart's dad is patting a dog.

859 Maggie's mum is patting a dog.

860 Lisa's mum is driving a car.

861 Lisa's mum is playing with blocks.

862 Bart's dad is eating an ice cream.

863 Maggie's mum is eating an ice cream. 
865 4. Name Name

866 Bart is pointing to Dad.

867 Lisa is touching Mum.

868 Bart is washing Dad.

869 Mum is dressing Maggie.

870 Dad is pointing to Bart.

871 Mum is touching Lisa.

872 Mum is washing Maggie.

873 Mum is dressing Lisa.

874

875

876 Appendix B. Obligatory Control Sentences

877 1. Single-Complement Subject Control

878 Maggie tried to wash Marge.

879 Homer tried to wash Bart.

880 Lisa tried to dress Marge.

881 Marge tried to dress Maggie.

882 Lisa tried to eat the sandwich.

883 Homer tried to eat the sandwich.

884 Bart tried to hit the punch bag.

885 Marge tried to hit the punch bag.

886

887 2. Object Control

888 Homer persuaded Marge to walk the dog.

889 Marge persuaded Homer to walk the dog.

890 Lisa persuaded Bart to build the sandcastle.

891 Bart persuaded Lisa to build the sandcastle.

892 Marge persuaded Maggie to get in the bath.

893 Marge persuaded Homer to read the book.

894 Homer persuaded Marge to drive the car.

895 Marge persuaded Maggie to pat the dog.

896

897 3. Double-Complement Subject Control 
898 Marge promised Homer to walk the dog.

899 Homer promised Marge to walk the dog.

900 Bart promised Lisa to play the trumpet.

901 Lisa promised Bart to play the trumpet.

902 Lisa promised Bart to write the letter.

903 Marge promised Homer to read the book.

904 Marge promised Homer to drive the car.

905 Maggie promised Marge to pat the dog.

906

907 4. SVO

908 Homer is walking the dog.

909 Lisa is eating a sandwich.

910 Lisa is throwing water.

911 Bart is playing the trumpet.

912 Marge is driving the car.

913 Maggie is patting the dog.

914 Maggie is having ice-cream.

915 Bart is swinging a bat.

916

917 Appendix C: Familiarization procedure

918

919 Prior to the experimental task, participants were presented with pictures depicting all

920 the characters of the Simpson family on the laptop computer. The first picture showed

921 all 5 members of the family together, and the experimenter pointed out to each

922 character individually to the child: 'This is Homer, he is the dad in this family. This is

923 Marge, she is the mum in this family. These are the children: Bart, Lisa and Maggie.'

924 To ensure that the child is able to see the difference between Lisa and her younger

925 sister Maggie, the experimenter would add: 'See Maggie has a dummy here, she is a 926 baby'.

927 The following sets of picture pairs were used to ensure that the child can distinguish

928 between the characters, select the appropriate character out of the two presented on 929 the screen, and understand that the correct picture can be on either left or right side 930 of the screen: 
1. Homer (left side) and Bart (right side), with the instruction: 'Point to Homer.'

2. Homer (left side) and Bart (right side), with the instruction: 'Point to Bart.'

3. Marge (left side) and Lisa (right side), with the instruction: 'Point to Marge.'

4. Marge (left side) and Lisa (right side), with the instruction: 'Point to Lisa.'

5. Lisa (left side) and Maggie (right side), with the instruction: 'Point to Lisa.'

6. Lisa (left side) and Maggie (right side), with the instruction: 'Point to baby Maggie.'

The presentation of the above pictures was followed by pictures showing relevant characters involved in an action described by the verbs used in the task: e.g. wash,

942 (Control).

943 The instructions uttered by the experimenter included sentences such as:

944 'Look, here we have washing/drying/touching/pointing. Marge is 945 washing/drying/touching/pointing to Maggie.' (Binding)

946 'Look, here we have driving/building/reading/walking/playing'. 'Homer is walking the 947 dog/driving the car/playing the trumpet.' (Control)

948 The experimenter would ensure that the participants can distinguish between the 949 characters before proceeding with the task. All the participants were able to follow 950 these instructions and were able to distinguish between the characters.

Appendix D: Questions used to determine knowledge of verbs independently of control and representative sample of responses.

Try: what does it mean when you try?

- It's when you do something and you're not sure you can do it.

- You might not be able to do it but if you really really want to do it you can do it.

- It's like you give it a go....but you might not be able to do it.

961 Persuade: what does it mean when you persuade someone?

- You make someone do something.

- You convince someone that they do it. 
- It's when you make someone do something.

Promise: what does it mean when you promise someone something?

- It's like when you say you'll definitely do it.

- I say l'll do something for sure.

- Once l've said I'll do it, I have to do it.

The promise question was followed up with: If you promise your mum that you will tidy up your room, does that mean that you do it or you don't do it?

- It means I do it.

- I do it... well if I keep my promise.

- I do it.

\section{Acknowledgements}

This research was supported by the British Academy (SG112896). Our warmest thanks to all of the children, staff and parents at Grange Park School, Thomas Tallis School, Clerkenwell Parochial CE Primary School, Greenacres Primary School, Hawkedon Primary School and The Rosary Catholic Primary School; to Rachel Gwynn, Nina Mehta, Anisa Mughal, Alexia Rontiris, Leonie Seek and Holly Strickland for help with data collection, and to Gordon Craig for statistical advice. We also thank three anonymous Lingua reviewers and audiences at the $14^{\text {th }}$ International Conference on Clinical Linguistics and Phonetics (University of Cork), Generative Approaches to Language Acquisition 2013 (University of Oldenburg), and the 35th Annual Conference of the German Linguistic Society 2013 (University of Potsdam).

\section{References}

Akker, S., van den, Hoeks, J., Spenader, J., Hendriks, P., 2012. Is the Dutch Delay of Principle B Effect dependent on verb type? In: Elenbaas, M., Aalberse S. (Eds.), Linguistics in the Netherlands, 1-14.

American Psychiatric Association. 2000. Diagnostic and Statistical Manual of Mental Disorders (IV-TR, $4^{\text {th }}$ edition). Washington, DC.

American Psychiatric Association. 2013. Diagnostic and Statistical Manual of Mental Disorders (5th edition). Washington, DC.

Ariel, M., 1988. Referring and accessibility. Journal of Linguistics 24 (1), 65 - 87. 
Ariel, M., 2004. Accessibility marking: Discourse functions, discourse profiles and processing cues. Discourse Processes 37 (2), 91 - 116.

999 Boeckx, C., Hornstein, N., 2004. Movement under control. Linguistic Inquiry 35, 431 1000452.

1001 Boucher, J., 2009. The Autistic Spectrum: Characteristics, Causes, and Practical 1002 Issues. Sage Publications Ltd, London.

1003 Broihier, K., Wexler, K., 1995. Children's acquisition of control in temporal adjuncts.

1004 In: C. Schutze, Ganger, J., Broihier, K. (Eds.), MITWPL 26, Cambridge, MA.

1005 Cairns, H., McDaniel, D., Hsu, J., Rapp, M., 1994. A longitudinal study of principles of 1006 control and pronominal reference in child English. Language 70, 260-288.

1007 Caplan, D., Hildebrandt, N., 1988. Disorders of Syntactic Comprehension. MIT Press.

1008 Chien, Y.-C., Wexler, K., 1990. Children's knowledge of locality conditions in binding 1009 as evidence for the modularity of syntax and pragmatics. Language Acquisition 1 (3), $1010 \quad 225-295$.

1011 Chomsky, C., 1969. The acquisition of syntax in children from 5 to 10. Research 1012 Monograph No. 57. MIT Press, Cambridge, Mass.

1013 Chomsky, N., 1986. Knowledge of Language: Its Nature, Origins and Use. Praeger, 1014 New York.

1015 Cohen Sherman, J., Lust, B., 1986. Syntactic and lexical constraints on the acquisition 1016 of control in complement sentences. In: Lust, B. (Ed.), Studies in the Acquisition of 1017 Anaphora, vol. I., Defining the Constraints. Springer Science and Business Media, 1018 Dordrecht. pp 279-310.

1019 Cohen Sherman, J., Lust, B., 1993. Children are in control. Cognition 43, 1-51.

1020 Cook, V., Newson, M., 2007. Chomsky's Universal Grammar. Blackwell, Oxford.

1021 Conroy, A., Takahashi, E., Lidz, J., Philips, C., 2009. Equal treatment for all 1022 antecedents: How children succeed with Principle B. Linguistic Inquiry, 45 (3), 4461023486.

1024 Culicover, P., Jackendoff, R., 2001. Remarks and replies: Control is not movement. 1025 Linguistic Inquiry 32, $493-512$.

1026 Durrleman, S., Zufferey, S., 2013. Investigating complex syntax in autism. In: S. 1027 Stavrakaki, S., Konstantinopoulou, P., Lalioti, M. (Eds.), Advances in Language 1028 Acquisition. Proceedings of GALA 2011. Cambridge Scholars Publishing, Newcastle. 
1029 Eisenberg, S., Cairns, H., 1994. The development of infinitives from three to five. 1030 Journal of Child Language 21, 713-734.

1031 Garraffa, M., Coco, M., Branigan, H., 2015. Effects of immediate and cumulative syntactic experience in language impairment: Evidence from priming of subject relatives in children with SLI. Language Learning and Development 11, 18 - 40.

1034 Goodluck, H., Terzi, A., Chocano Diaz, G., 2000. The acquisition of control cross1035 linguistically: structural and lexical factors in learning to license PRO. Journal of Child 1036 Language 28, 153-172.

1037 Grodzinsky, Y., Reinhart, T., 1993. The innateness of binding and coreference. 1038 Linguistic Inquiry, 24, 69-101.

1039 Guasti, M, T., 2004. Language Acquisition: The Growth of Grammar. MIT Press, 1040 Cambridge, Mass.

1041 Haegeman, L., 1994. (2nd edition). Introduction to Government and Binding Theory. 1042 Blackwell, Oxford.

1043 Happé, F., 1993. Communicative competence and theory of mind in autism: A test of 1044 relevance theory. Cognition 48, 101-119.

1045 Hirsch, C., Wexler, K., 2007. The late development of raising: What children seem to 1046 think about seem. In: Davies, W., Dubinsky, S. (Eds.), New Horizons in the Analysis 1047 of Control and Raising. Springer, Dordrecht.

1048 Hornstein, N., 2001. Move! A Minimalist Theory of Construal. Blackwell Publishers, 1049 Oxford.

1050 Hsu, J., Cairns, H. S., Eisenberg, S., Schlisselberg, G., 1989. Control and coreference 1051 in early child language. Journal of Child Language 16, $599-622$.

1052 Isac, D., Reiss, C., 2013. I-Language: An Introduction to Linguistics as Cognitive 1053 Science. Oxford. Oxford University Press, Oxford.

1054 Jaeger, T., 2008. Categorical data analysis: Away from ANOVAs (transformation or not) and towards Logit Mixed Models. Journal of Memory and Language 59, 434-446.

1056 Jakubowicz, C., 1984. On markedness and binding principles. Proceedings of NELS. 1057 GLSA, University of Massachussetts, Amherst, 154-182.

1058 Janke, V., 2007. Control without PRO. Doctoral Thesis, University College London. 1059 Janke, V., 2008. Control without a subject. Lingua 118 (1), 82 -118.

1060 Janke, V., 2013. Non-obligatory control and its + human interpretation. In: Kolokonte, 1061 M., Janke, V. (Eds.), Interfaces in Language 3. Cambridge Scholars Publishing, 
Newcastle.

1063 Janke, V., and Perovic, A., (accepted) Advanced syntax and primary pragmatics in 1064 children with ASD. In: Naigles, L. (Ed.), Innovative Investigations in Autism Spectrum 1065 Disorders. APA/De Gruyter Mouton.

1066 Kirby, S., Davies, W., Dubinsky, S., 2010a. Up to D(eb)ate on raising and control. Part

1067 1: Properties and analyses of the constructions. Language and Linguistics Compass $10684(6), 390-400$.

1069 Kirby, S., Davies, W., Dubinsky, S., 2010b. Up to D(eb)ate on raising and control Part 1070 2: The empirical range of the constructions and research on their acquisition. 1071 Language and Linguistics Compass 4 (6), 401 - 416.

1072 Kjelgaard, M., Tager-Flusberg, H., 2001. An investigation of language impairment in 1073 autism: Implications for genetic subgroups. Language and Cognitive Processes 16 (21074 3), 287-308.

1075 Koster, J., 1987. Domains and Dynasties. Foris, Dordrecht.

1076 Landau, I., 2000. Elements of Control: Structure and Meaning in Infinitival 1077 Constructions. Kluwer Academic Publishers, Dordrecht.

1078 Landau, I., 2013. Control in Generative Grammar: A Research Companion. 1079 Cambridge University Press, Cambridge.

1080 Lasnik, H., 1992. Two notes on control and binding. In: Larson, R., latriadou, S., Lahiri, 1081 U., Higginbotham, J. (Eds.), Control and Grammar. Kluwer Academic Publishers, 1082 Amsterdam, pp $235-251$.

1083 Manzini, R., 1983. On control and control theory. Linguistic Inquiry 14, 421-46.

1084 McDaniel, D., Cairns, H., Hsu, J., 1990/1. Control principles in the grammar of young 1085 children. Language Acquisition, 1 (4), 297-335.

1086 Norbury, C., 2005. The relationship between theory of mind and metaphor: evidence 1087 from children with language impairment and autistic spectrum disorder. British Journal 1088 of Developmental Psychology 23, 383-399.

1089 Perovic, A., 2004. Knowledge of binding in Down syndrome: Evidence from English 1090 and Serbo-Croatian. Doctoral Thesis, University College London.

1091 Perovic, A. 2006. Syntactic deficit in Down syndrome: More evidence for the modular 1092 organisation of language. Lingua 116 (10), 1616-1630.

1093 Perovic, A., Wexler, K., 2007. Complex grammar in Williams syndrome. Clinical 1094 Linguistics and Phonetics 21, 729-745. 
1095 Perovic, A., Modyanova, N., Wexler, K., 2007. Knowledge of c-command and A-

1096 movement in children and adolescents with autism and with Asperger syndrome.

1097 Paper presented at Generative Approaches to Language Acquisition (GALA).

1098 Barcelona, Spain.

1099 Perovic, A., Modyanova, N., Wexler, K., 2013a. Comparison of reflexive and personal

1100 pronouns in children with autism: A syntactic or pragmatic deficit? Applied

1101 Psycholinguistics, 34 (4), 813-835.

1102 Perovic, A., Modyanova, N., Wexler, K., 2013b. Comparisons of grammar in 1103 neurodevelopmental disorders: The case of binding in Williams syndrome and autism 1104 with and without language impairment. Language Acquisition, 20, 133-154.

1105 Perovic, A., and Janke, V., 2013 Issues in the acquisition of binding, control and

1106 raising in high-functioning children with autism. UCL Working Papers in Linguistics,

$1107 \quad 25,131-144$.

1108 Pinker, S., 1984. Language Learnability and Language Development. Harvard 1109 University Press, Cambridge, MA.

1110 Quene, H., Van Der Bergh, H., 2008. Examples of mixed effects modeling with crossed

1111 random effects and with binomial data. Journal of Memory and Language 59, 4131112425.

1113 Radford, A., 2004. Syntax: A Minimalist Introduction. Cambridge Univeristy Press, 1114 Cambridge.

1115 Reinhart, T., 1981. Pragmatics and linguistics: An analysis of sentence topics. 1116 Philosophica 27, 53 - 94.

1117 Riches N., Loucas, T., Charman, T., Simonoff E., Baird, G., 2010. Sentence 1118 repetition in adolescents with Specific Language Impairment and autism: an 1119 investigation of complex syntax. International Journal of Language and 1120 Communication Disorders 45 (1), 47-60.

1121 Ring, M., Clahsen, H., 2005. Distinct patterns of language impairment in Down 1122 syndrome, Williams syndrome and SLI: The case of syntactic chains. Journal of 1123 Neurolinguistics 19, 479-501.

1124 Rizzi, L., 2013. Locality. Lingua 130, 169 - 186.

1125 Rooryck, J., 2007. Control via selection. In: Davies, W., Dubinsky, S. (Eds.), New 1126 Horizons in the Analysis of Control and Raising. Springer, Dordrecht. 
1127 Rosenbaum, P, S., 1967. The Grammar of English Predicate Complement

1128 Constructions. MIT Press, Cambridge, Mass.

1129 Rundblad, G., Annaz, D., 2010. The atypical development of metaphor and metonymy

1130 comprehension in children with autism. Autism 14, $29-47$.

1131 Samek-Lodovici, V., 1996. Constraints on Subjects: An Optimality Theoretic Analysis.

1132 Doctoral Thesis, Rutgers.

1133 Sanoudaki, E., Varlokosta, S., 2014. Pronoun comprehension in individuals with Down 1134 syndrome: deviance or delay? Journal of Speech, Language and Hearing Research $113557,1442-1452$.

1136 Tager-Flusberg, $H$., 1981. On the nature of linguistic functioning in early infantile 1137 autism. Journal of Autism and Developmental Disorders 11, 45-56.

1138 Tager-Flusberg, H., Anderson, M., 1991. The development of contingent discourse 1139 ability in autistic children. Journal of Child Psychology and Psychiatry 32, 1123-34.

1140 Tavakolian, S. L., 1978. Children's comprehension of pronominal subjects and missing 1141 subjects in complicated sentences. In: Goodluck, H., Solan, L. (Eds.), Papers in the 1142 Structure and Development of Child Language. UMASS Occasional Papers in 1143 Linguistics 4, 145-152.

1144 Thornton, R., Crain, S., 1994. Successive cyclic movement. In: Hoesktra, J., Schwartz, 1145 B. (Eds.), Language Acquisition Studies in Generative Grammar. John Benjamins, 1146 Amsterdam.

1147 De Villiers, J., Roeper, T., Vainikka, A., 1990. The acquisition of long-distance rules.

1148 In: Frazier, L., De Villiers, J. (Eds.), Language Processing and Language Acquisition.

1149 Kluwer, Boston, 257-297.

1150 Wexler, K., Chien, Y.-C., 1985. The development of lexical anaphors and pronouns.

1151 Papers and Reports on Child Language Development, 24, 138-149.

1152 Williams, E., 1980. Predication. Linguistic Inquiry 11, 203 - 238.

1153 World Health Organisation., 1992. ICD-10 Classifications of Mental and Behavioural 1154 Disorder: Clinical Descriptions and Diagnostic Guidelines. Geneva.

1155 Zebib R., Tuller, L., Prévost, P., Morin, E., 2013. Formal language impairment in 1156 French-speaking children with ASD: A comparative ASD/SLI Study. In: Stavrakaki, S., 1157 Lalioti, M., Konstantinopoulou, P. (Eds.), Advances in Language Acquisition. 1158 Proceedings of GALA 2011. Cambridge Scholars Publishing, Newcastle. 